\title{
The Cross-talk Relationship between Metformin and Gut Microbiota
}

\section{Hyder O. Mirghani. MD, M.Sc.}

Associate Professor of Internal Medicine and Endocrine, Medical Department, Faculty of Medicine, University of Tabuk, KSA

Corresponding Author: Hyder O. Mirghani; Faculty of Medicine, University of Tabuk, PO Box 3378 Tabuk 51941, Saudi

Arabia

email:

s.hyder63@hotmail.com

Received 3 November 2020

Accepted 18 December 2020

Published 31 December 2020

Production and Hosting by Knowledge E

(c) Hyder O. Mirghani. This article is distributed under the terms of the Creative

Commons Attribution

License, which permits unrestricted use and redistribution provided that the original author and source are credited.

Editor-in-Chief:

Prof. Mohammad A. M. Ibnouf

\section{Abstract}

Background: Metformin is the first-line oral therapy for type 2 diabetes mellitus. However, its mode of action is poorly defined. There is an increasing awareness regarding the cross talk of gut microbiota and metformin. The current review aimed to assess the bidirectional relationship between metformin and gut microbiota.

Methods: Electronic search was conducted in Pub Med and the first 100 articles in Google Scholar published until November 2019. However, only randomized controlled trials on humans published in the English language were included. The terms "gut microbiota," "gut flora "and "metformin" were as keywords to perform the search. Although 124 articles were retrieved, only six met the inclusion criteria of the study.

Results: Of the six full texts of randomized controlled trials included in the study, two-thirds were published in Europe, one in the USA, and one in China. Six hundredthirty five patients were included and the duration of the studies ranged from seven days to six months. The studies concluded that microbiota modulates some metformin actions on plasma glucose; while metformin enhances the abundance of microbiota that positively affect insulin resistance and plasma glucose.

Conclusion: The current review showed that microbiota dysbiosis may mediate metformin antidiabetic effects. Whereas metformin shifted the gut microbiota toward the beneficial species ameliorating insulin resistance. The present study might provide insights into a novel therapeutic approach to treat type 2 diabetes mellitus.

Keywords: gut microbiota, metformin, type 2 diabetes

\section{Introduction}

Over decades of clinical use as the first-line drug for the treatment of diabetes mellitus, metformin has proved to be safe and well tolerated. Metformin enhances insulin action in the liver and skeletal muscles to decrease insulin production and increase nonoxidative disposal of glucose. When taken together, these actions reduce insulin in the hyperglycemic state with little potential for hypoglycemia [1]. However, the mechanism of action of metformin is not completely understood. There is an increasing awareness about the role of the gastrointestinal tract in the regulation of plasma glucose, mainly through microbiota effects on incretins, bile acids, and glucagon-like peptide [2]. 
The inhibition of the mitochondrial respiratory chain mediated by activation of adenosine monophosphate-activated protein kinase (AMPK) thought as the center of metformin action has been challenged and it may account for indirect changes in insulin sensitivity [3]; blocking this pathway is not followed by loss of metformin effects on glucose. In addition, oral metformin is more effective than intravenous, raising the possibility of an important gut role.

The gut microbiota is the first protection system of the gastrointestinal tract; it is composed of thousands of species and more than 15,000 kinds of bacteria in weight equal to $1 \mathrm{~kg}$ [4]. Recent studies showed that the gut microbiota might play an important role in the pharmacodynamics and pharmacokinetics of metformin, while the drug metformin alters the functional capacity of gut microbiota $[5,6]$. The gut microbiota is an area of extensive research due to its associations with various diseases including diabetes mellitus. An interesting recent study conducted among patients with type 2 diabetes mellitus (50\%), overweight/obesity (78\%), co-morbid psychiatric (65\%), and opioid use (45\%) disorders in the USA concluded the interaction between metformin, gut microbiota, and opioid use [7].

The current review assessed the role of metformin on the gut microbiota, and whether the gut microbiota mediates the actions of metformin.

\section{Methods}

An electronic search was conducted in Pub Med database and the first 100 articles in Google Scholar for relevant articles in the English language; the search was limited to randomized controlled trial on humans from the first published article to November 2019. The terms "gut flora" "metformin," and "gut microbiota were used as keywords with protean and/or OR. Articles published in languages other than English and studies on animals were not included. One hundred twenty-four articles were retrieved. The titles and abstracts of the articles were screened for the removal of duplications and irrelevant articles. Only six articles fulfilled the inclusion criteria. Figure 1 illustrates the different phases of the search process.

\section{Results}

The six selected randomized controlled trials (four from Europe, one from the USA, and one from Asia) included 635 patients who received metformin for a duration ranging from seven days to six months, the dose ranged from $1 \mathrm{gr} /$ day to $1.7 \mathrm{gr} /$ day. All studies showed that metformin altered microbiota and improved glucose tolerance. In addition, metformin increased the gut microbiota species with positive effects on insulin resistance and plasma glucose, some studies reported a favorable effect on lipids as well (Table 1). 

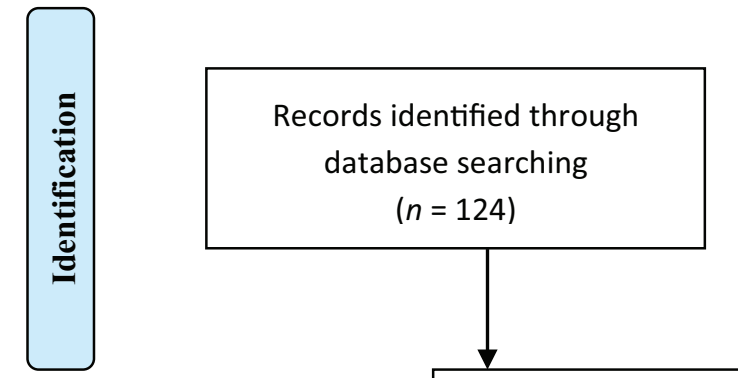

Additional records identified through other sources $(n=0)$; no other sources

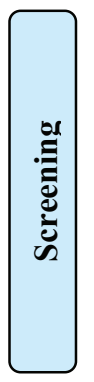

Records after duplicates removed

$(n=111)$
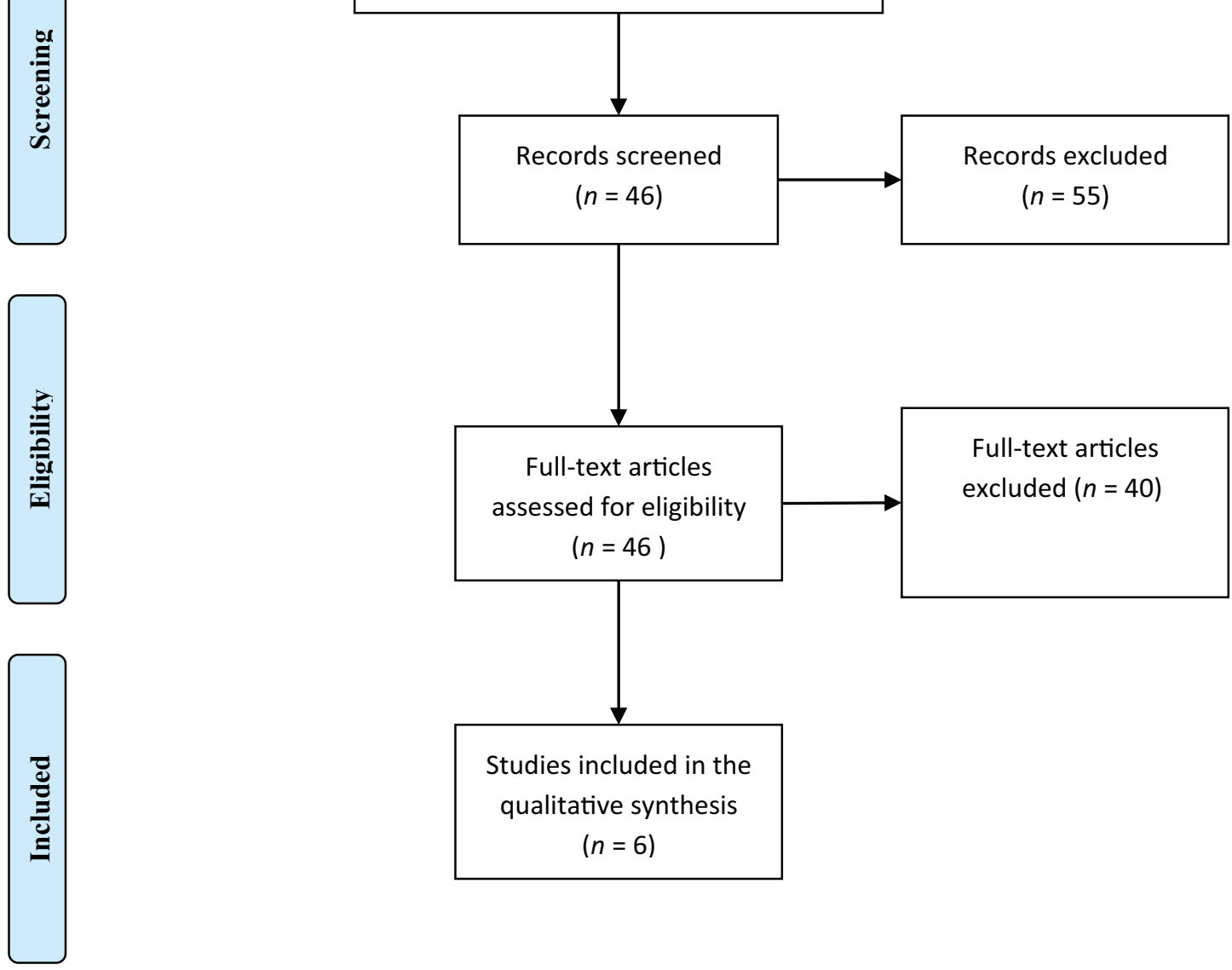

Records excluded $(n=55)$

Figure 1: Flow diagram of the different phases of the systematic review (PRISMA flowchart).

\section{Discussion}

In the present review of randomized controlled studies, Napolitano et al. [8] assessed 14 patients on metformin $1000 \mathrm{mg} /$ day and followed them up for three months. The study assessed gut microbiota, gut hormones including glucagon-like peptide-1 (GLP-1), peptide tyrosine-tyrosine, glucose-dependent insulinotropic peptide), and blood and fecal bile acids at four points (baseline, after metformin withdrawal, when the fasting plasma glucose was $25 \%$ above normal, and after the drugs were reintroduced. The researcher observed an increased level of GLP-1 and reduction in bile acids with 
TABLE 1: The relationship between metformin and gut microbiota.

\begin{tabular}{|c|c|c|c|c|c|}
\hline Author & Year & Country & $\begin{array}{l}\text { Number of } \\
\text { patients }\end{array}$ & Study duration & Results \\
\hline $\begin{array}{l}\text { Napolitano } \\
\text { et al. }\end{array}$ & 2014 & UK & 14 & $\begin{array}{l}\text { Three months on } \\
\text { metformin } 1000 \\
\text { mg/day }\end{array}$ & $\begin{array}{l}\text { Metformin changed gut } \\
\text { microbes ( phylum Firmicutes } \\
\text { and Bacteroidetes abundance) in } \\
\text { patients with type } 2 \text { diabetes }\end{array}$ \\
\hline Burton et al. & 2015 & USA & 14 & $\begin{array}{l}\text { Two weeks on } \\
1500 \text { mg/day with } \\
\text { microbiome } \\
\text { modulator }\end{array}$ & $\begin{array}{l}\text { Microbiome modulator (NM504) } \\
\text { in addition to metformin } \\
\text { increased efficacy and } \\
\text { tolerability of the drug }\end{array}$ \\
\hline $\begin{array}{l}\text { Pendersen } \\
\text { et al. }\end{array}$ & 2016 & UK & 29 patients & $\begin{array}{l}\text { Prebiotics for } 21 \\
\text { weeks }\end{array}$ & $\begin{array}{l}\text { No effect of prebiotics on } \\
\text { microbiota proposed that } \\
\text { metformin may play a role }\end{array}$ \\
\hline Wu et al. & 2017 & Sweden & & $\begin{array}{l}120 \text { days on } \\
\text { metformin or } \\
\text { placebo with a } \\
\text { washout period }\end{array}$ & $\begin{array}{l}\text { Microbiota mediates some } \\
\text { metformin antidiabetic effects; } \\
\text { moreover, fecal transplantation } \\
\text { from metformin-treated patients } \\
\text { improved glycemia among mice }\end{array}$ \\
\hline Albere et al. & 2018 & Latvia & 18 & $\begin{array}{l}\text { Metformin } 850 \\
\text { twice daily for } \\
\text { seven days }\end{array}$ & $\begin{array}{l}\text { Metformin had an immediate } \\
\text { effect on gut microbiota }\end{array}$ \\
\hline Tong et al. & 2018 & China & 400 & 12 weeks & $\begin{array}{l}\text { Metformin shifted the gut } \\
\text { microbiota (the abundance of } \\
\text { the Blautia spp. that improved } \\
\text { insulin resistance), ameliorated } \\
\text { hyperlipidemia, and improved } \\
\text { glycemic control }\end{array}$ \\
\hline
\end{tabular}

metformin, while the reverse happened with metformin withdrawal. Furthermore, the researchers observed that the abundance of Bacteroidetes was negatively correlated with changes in cholic acid and conjugates, while phylum Firmicutes abundance was positively correlated. These results imply that metformin exerts gut-based pharmacology. A study published in the United States [9] found that the addition of microbiome modulator to metformin increased both efficacy and tolerability in the form of glucose profile improvement and lesser gastrointestinal manifestations (the most common side effects of metformin). The aforementioned findings supported the previous observations regarding the role of gut microbiota on metformin. Also, it may pave the way for more use of this essential first-line antidiabetic medication. Pendersen et al. [10] assessed the effects of prebiotics on gut microbiota and found no positive results. However, the authors proposed that metformin might play a role. A study [11] with a long period of follow-up (120 days) observed that microbiota mediates some metformin antidiabetic effects; moreover, fecal transplantation from metformin-treated patients improved glycemia among mice. This observation suggested that metformin may play a major role in fecal transplantation, and supporting the previous finding, fecal transplantation was an effective measure including diabetes mellitus, autism, and inflammatory bowel disease among various diseases [12-14]. It is interesting to note that metformin had an immediate effect on the gut microbiota starting from the first $24 \mathrm{hr}$ [15], a study with a relatively large sample size [16] showed that metformin shifted the gut microbiota, ameliorated hyperlipidemia, and improved glycemic control. 


\section{Conclusion}

The current review showed that microbiota dysbiosis might mediate the antidiabetic effects of metformin. While metformin shifted the gut microbiota toward the beneficial species, the current review showed that gut microbiota might serve as a promising target for diabetes control, which has become a worldwide public health threat.

\section{Acknowledgements}

The author would like to acknowledge Dr. Abdullah Hammad EL-Temani, Associate Professor of Family Medicine, Department of Family Medicine, Faculty of Medicine, University of Tabuk, Saudi Arabia for revising this manuscript

\section{Ethical considerations}

The study has been approved by the University of Tabuk, Saudi Arabia.

\section{Competing interests}

The author declares that there are no conflicts of interest.

\section{Availability of data and material}

The data included in the study is available upon reasonable request

\section{Funding}

None

\section{References}

[1] Hostalek, U., Gwilt, M., and Hildemann, S. (2015). Therapeutic use of metformin in prediabetes and diabetes prevention. Drugs, vol. 75, no. 10, pp. 1071-1094. doi:10.1007/s40265-015-0416-8

[2] Sansome, D. J., Xie, C., Veedfald, S., et al. (2019). Mechanism of glucose lowering by metformin in type 2 diabetes: role of bile acids. Diabetes, Obesity and Metabolism, vol. 22, no. 2, pp. 141-148. doi:10.1111/dom.13869

[3] Foretz, M., Guigas, B., and Viollet, B. (2019). Understanding the glucoregulatory mechanisms of metformin in type 2 diabetes mellitus. Nature Reviews Endocrinology, vol. 15, no. 10, pp. 569-589. doi:10.1038/s41574-019-0242-2

[4] Mangiola, F., laniro, G., Franceschi, F., et al. (2016). Gut microbiota in autism and mood disorders. World Journal of Gastroenterology, vol. 22, no. 1, pp. 361-368. doi:10.3748/wjg.v22.i1.361

[5] Wu, B., Chen, M., Gao, Y., et al. (2019). In vivo pharmacodynamic and pharmacokinetic effects of metformin mediated by the gut microbiota in rats. Life Sciences, vol. 226, pp. 185-192. doi:10.1016/j.lfs.2019.04.009

[6] Caesar, R. (2019). Pharmacologic and nonpharmacologic therapies for the gut microbiota in type 2 diabetes. Canadian Journal of Diabetes, vol. 43, no. 3, pp. 224-231. doi:10.1016/j.jcjd.2019.01.007 
[7] Barengolts, E., Green, S. J., Eisenberg, Y., et al. (2018). Gut microbiota varies by opioid use, circulating leptin and oxytocin in African American men with diabetes and high burden of chronic disease. PLOS ONE, vol. 13, no. 3, p. e0194171. doi:10.1371/journal.pone.0194171

[8] Napolitano, A., Miller, S., Nicholls, A. W., et al. (2014). Novel gut-based pharmacology of metformin in patients with type 2 diabetes mellitus. PLOS ONE, vol. 9, no. 7, p. e100778. doi:10.1371/journal.pone.0100778

[9] Burton, J. H., Johnson, M., Johnson, J., et al. (2015). Addition of a gastrointestinal microbiome modulator to metformin improves metformin tolerance and fasting glucose levels. Journal of Diabetes Science and Technology, vol. 9, no. 4, pp. 808-814. doi:10.1177/1932296815577425

[10] Pedersen, C., Gallagher, E., Horton, F., et al. (2016). Host-microbiome interactions in human type 2 diabetes following prebiotic fiber (galactooligosaccharides) intake. British Journal of Nutrition, vol. 116, no. 11, pp. 1869-1877. doi:10.1017/S0007114516004086

[11] Wu, H., Esteve, E., Tremaroli, V., et al. (2017). Metformin alters the gut microbiome of individuals with treatment-naive type 2 diabetes, contributing to the therapeutic effects of the drug. Nature Medicine, vol. 23, no. 7, pp. 850-858. doi:10.1038/nm.4345

[12] Bordalo Tonucci, L., Dos Santos, K. M., De Luces Fortes Ferreira, C. L., et al. (2017). Gut microbiota and probiotics: focus on diabetes mellitus. Critical Reviews in Food Science and Nutrition, vol. 57, no. 11, pp. 2296-2309. doi:10.1080/10408398.2014.934438

[13] Sanctuary, M. R., Kain, J. N., Chen, S. Y., et al. (2019). Pilot study of probiotic/colostrum supplementation on gut function in children with autism and gastrointestinal symptoms. PLOS ONE, vol. 14, no. 1, p. e0210064. doi:10.1371/journal.pone.0210064

[14] Paramsothy, S., Nielsen, S., Kamm, M. A., et al. (2019). Specific bacteria and metabolites associated with response to fecal microbiota transplantation in patients with ulcerative colitis. Gastroenterology, vol. 156, no. 5, pp. 1440-1454.e2. doi:10.1053/j.gastro.2018.12.001

[15] Elbere, I., Kalnina, I., Silamikelis, I., et al. (2018). Association of metformin administration with gut microbiome dysbiosis in healthy volunteers. PLOS ONE, vol. 13, no. 9, p. e0204317. doi:10.1371/journal.pone.0204317

[16] Tong, X., Xu, J., Lian, F., et al. (2018). Structural alteration of gut microbiota during the amelioration of human type 2 diabetes with hyperlipidemia by metformin and a traditional Chinese herbal formula: a multicenter, randomized, open label clinical trial. MBio, vol. 9, no. 3, pii: e02392-17. doi:10.1128/mBio.02392-17 